\title{
Synthesis and Biological Evaluation of Prodrugs For Nitroreductase Based 4- $\beta$-Amino-4'- Demethylepipodophyllotoxin As Potential Anticancer Agents
}

\section{Zhengrong Wu ( $\nabla$ wuzhengrong@lzu.edu.cn ) Lanzhou University \\ Wei Deng \\ Lanzhou Medical College: Lanzhou University \\ Dian $\mathrm{He}$ \\ Lanzhou Medical College: Lanzhou University}

\section{Research Article}

Keywords: Podophyllotoxin, O-nitrophenoxyacetyl acid, Cell cycle arrest, Apoptosis, Structure-Activity Relationship

Posted Date: December 22nd, 2021

DOI: https://doi.org/10.21203/rs.3.rs-1158885/v1

License: (c) (1) This work is licensed under a Creative Commons Attribution 4.0 International License. Read Full License

Version of Record: A version of this preprint was published at Medicinal Chemistry Research on January 24th, 2022. See the published version at https://doi.org/10.1007/s00044-022-02847-5. 


\section{Abstract}

A series of prodrugs for nitroreductase based 4- $\beta$-amino-4'- Demethylepipodophyllotoxin as potential anticancer agents were synthesized, and their antiproliferative activities in vitro showed compounds $\mathbf{2 b}$ $\left(\mathrm{IC}_{50}=0.77,0.83\right.$ and $\left.1.19 \mu \mathrm{M}\right)$ and $\mathbf{2 d}\left(\mathrm{IC}_{50}=0.98,0.91\right.$ and $\left.1.58 \mu \mathrm{M}\right)$ were greatly selectively toxic to tumor cells A-549, HeLa and HepG2, respectively, and lower damage to normal WI-38 cells in comparison with positive agent Etoposide and Demethylepipodophyllotoxin, and induced cell cycle arrest in the G2/M phase with a concomitant decrease in the population of G1 phase in HeLa cells, which were accompanied by apoptosis. Furthermore, Molecular docking model showed that compounds $\mathbf{2} \mathbf{b}$ and $\mathbf{2} \mathbf{d}$ appeared to form stable bonds with NTR 1DS7. Taken together, these conjugates have the potential to be developed as anti-tumor drugs.

\section{Introduction}

With the rapid growth of cancer cases across the globe, a great number of approaches are being investigated to develop an effective cure for this deadly disease [1]. Among various approaches, naturally occurring substances account for the abundant sources to identify novel hits and leads. However, a number of antitumor naturally-occurring substances do not show target specificity, which may even show adverse toxicity to non-carcinoma cells. In order to reduce the cytotoxicity of the natural compounds, appropriate structural modification is the vital way and has been adopted to develop new drug [2].

Podophyllotoxin is a natural occurring aryltetralin lignin with pronounced cytotoxic activity. However, its clinical application for cancer treatment has been blocked due to its poor water solubility and selectivity [3]. For reducing cytotoxicity and increasing water solubility of the bioactive compound, a great number of structural modification have been adopted to address these limitations and obtain better therapeutic agents [4-9], and these efforts have led to the structure-activity relationships (SAR) unambiguously demonstrate that $\mathrm{C} 4$ is the major molecular area tolerable to significant structural diversification [10]. Therefore, most of the current derivatization on Podophyllotoxin focuses on C-4 position. Recently, A series of $4 \beta-N$ substituted 4'-O-demethyl-4-deoxyp-odophyllotoxins have been synthesized, and exhibited significant anticancer activity [11-15], Among these, the substituent of $p$-nitrobenzylpiperazine markedly affected the activity profiles of this compound class, and may serve as a potential anti-cancer drug [16].

Prodrug strategies based on nitroreductases (NTR) have been extensively studied in recent years. NTR can catalyze nitro-substituted aromatic compounds into aromatic amines and undergoes internal cyclization to a non-toxic derivative, which reduces serious side effects on healthy cells and increases concentration of drugs at cancer cells is remarkable. So the discoveries of new prodrugs/NTR combinations which are of increasing interest as potential cancer therapeutics [17-22].

O-nitrophenoxyacetyl acid have known as potential inhibitors of vascular endothelial growth factor (VEGF) in cancer chemotherapy. NTR can catalyze nitro substituent into aromatic amines and undergoes 
internal cyclization to a non-toxic derivative, which reduces serious side effects on healthy cells and increases concentration of drugs at cancer cells is remarkable [23].

Inspired by the above background, herein, we present the design, synthesis, of a novel series of $4 \beta-N-(4-$ Nitrophenyl piperazinyl)-4'-O-demethyl-4- deoxypodophyllotoxin and four different $O$-nitrophenoxyacetyl acids(substituent of electron-donating groups, electron-withdrawing groups, steric groups, comprehensive groups, respectively) hybrid and evaluation of their cytotoxic activity against several cancer cell lines.

\section{Results And Discussion Synthesis}

The synthetic route to the target compounds is shown in Scheme 1 . The $O$-nitrophenoxyacetyl acids were prepared according to our previous report [24]. 4ß-N-(4-Nitrophenyl piperazinyl)-4'-O-demethyl-4deoxypodophyllotoxin was according to the procedure described previous [16]. The chemical structures of the final compounds were fully characterized by ${ }^{1} \mathrm{H}$ NMR, ${ }^{13} \mathrm{C}$ NMR and HRMS spectroscopic techniques.

\section{Cytotoxicity}

The in vitro cytotoxicities of conjugates $2 a-2 t$ were evaluated against a panel of three human cancer cell lines (lung carcinoma A-549, cervical carcinoma HeLa, hepatocellular carcinoma HepG2, and human embryonic lung fibroblasts WI-38 cells), with Etoposide and Demethylepipodophyllotoxin as reference compounds. In addition, their toxicity evaluation was tested on normal embryonic lung fibroblast WI-38 cells. The screening procedure was based on the standard MTT growth inhibition assay, and the results are summarized in Table 1. As shown, most of the compounds were more potent against three tumor cell, these compounds were most effective in A549 cells and HeLa cells, and had lowest potency in HepG2 cells. The $\mathrm{IC}_{50}$ value of compounds $\mathbf{2 b}(0.77,0.83$ and $1.19 \mu \mathrm{M})$ and $\mathbf{2 d}(0.98,0.91$ and $1.58 \mu \mathrm{M})$, and which were comparable to positive agent Etoposide and more potent than the positive agent Demethylepipodophyllotoxin (9.64, 15.29 and $12.73 \mu \mathrm{M})$ for HeLa, HepG2 and A549 cells. In comparison, compounds $2 \mathrm{~b}\left(\mathrm{IC}_{50}=688.54 \mu \mathrm{M}\right)$ and $\mathbf{2 d}\left(\mathrm{IC}_{50}=477.96 \mu \mathrm{M}\right)$ showed greater selectivity, and were relatively less active toward normal WI-38 cells in comparison with positive agent Etoposide $\left(\mathrm{IC}_{50}<100 \mu \mathrm{M}\right)$ and Demethylepipodophyllotoxin $\left(\mathrm{IC}_{50}<100 \mu \mathrm{M}\right)$. Based on these results, it was possible to deduce some preliminary SAR. First of all, 0 -nitrophenoxyacetyl acids with electron-donating group substitution (2a-2e) appeared to be more potent than those with electron-withdrawing (2f-2k), steric (2l-2o), and comprehensive (2p-2t) groups. 
Table 1

Cytotoxicity of target compounds to different cells following $24 \mathrm{~h}$ of exposure.

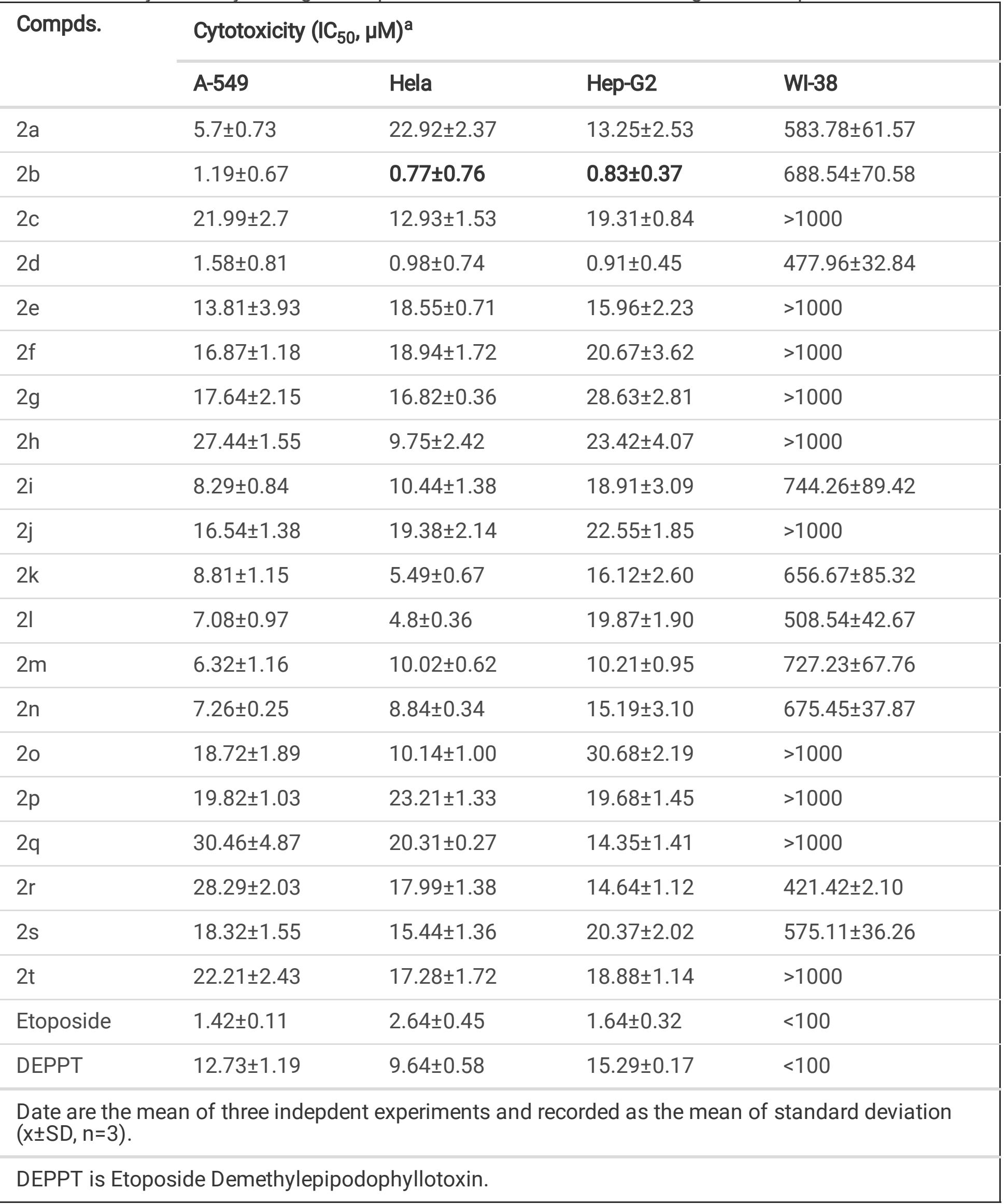




\section{Cell cycle arrest and apoptotic assay}

The data above reveled that compounds $\mathbf{2} \mathbf{b}$ and $\mathbf{2} \mathbf{d}$ the most potent and selective were further investigate the effects on cell cycle progression by means of fluorescence-activated cell sorting analysis of HCT-116 cells stained with propidium iodide.

As shown in Fig. $\mathbf{1}$, treatment with compounds $\mathbf{2} \mathbf{b}$ and $\mathbf{2} \mathbf{d}$ led to a dose-dependent accumulation of cells in the G2/M phase with a concomitant decrease in the population of G1 phase cells respectively, compared with untreated cultures and Etoposide. Similar effects also occurred with the Annexin V/PI apoptosis detection (Fig. 2). These results demonstrated that compounds $\mathbf{2} \mathbf{b}$ and $\mathbf{2} \mathbf{d}$ were interfering with cell proliferation by arresting the cell cycle and induced G2/M arrest accompanied by apoptosis in HeLa cells.

\section{Molecular docking assay}

To prove the anticancer mechanism of the action, a molecular docking investigation was undertaken. As shown in Fig. 3 , which revealed that compounds $2 b$ and $2 d$ were well inserted into the two active pockets of NTR 1DS7, Hydrogen bonds were shown with yellow dash lines and dark green spheres. The hydrophobic interactions which are van der Waals were represented by light green spheres, these results reveal that compounds $2 \mathrm{~b}$ and $2 \mathrm{~d}$ having hydrophobic property, good membrane permeability and specifically targeting NTR. The binding forms are demonstrated that the para nitro and carbonyl groups in phenyl ring were able to affect the interaction on NTR significantly. These data provide certain theoretical support for experimental results.

\section{Conclusions}

In conclusion, we have designed and synthesized a number of prodrugs for nitroreductase based 4- $\beta$ amino-4'- Demethylepipodophyllotoxin as potential anticancer agents were synthesized, and their antiproliferative activities in vitro showed compounds $\mathbf{2 b}$ and $\mathbf{2 d}$ were greatly selectively toxic to tumor cells A-549, HeLa and HepG2, respectively, and lower damage to normal WI-38 cells in comparison with positive agent Etoposide and Demethylepipodophyllotoxin, and induced cell cycle arrest in the G2/M phase with a concomitant decrease in the population of G1 phase in HeLa cells, which were accompanied by apoptosis. Furthermore, Molecular docking model showed that compounds $\mathbf{2} \mathbf{b}$ and $\mathbf{2 d}$ appeared to form stable bonds with NTR 1DS7. Taken together, these conjugates have the potential to be developed as anti-tumor drugs. Further studies on the relevant action mechanisms and structural modification of identified hits are on-going.

\section{Materials And Methods}

\section{Chemistry}


All reactions were performed with commercially available reagents and solvents without further purification. All reactions were monitored by thin-layer chromatography (TLC). ${ }^{1} \mathrm{H}$ and ${ }^{13} \mathrm{C}$ NMR spectra were recorded on Bruker AVANCE-III HD 400MHz or NEO 500MHz (Bruker Daltonics Inc., Germany) spectrometers using TMS as a reference. Mass spectra were recorded on a Bruker APEXII49e spectrometer (Bruker Daltonics Inc., Germany) with ESI source as ionization.

Data for Compound 2-(3-methyl-2-nitrophenoxy)acetic acid-4ß-N-(4-Nitrophenyl piperazinyl)- 4'-0demethyl-4-deoxypodophyllotoxin (2a). ${ }^{1} \mathrm{H}$ NMR (400 MHz, DMSO- $\left.d_{6}, \mathrm{TMS}, \mathrm{ppm}\right): \delta: 8.06$ (d, J=9.2Hz, 2H), $7.49(\mathrm{t}, J=8.0 \mathrm{~Hz}, 1 \mathrm{H}), 7.43(\mathrm{~s}, 1 \mathrm{H}), 7.1(\mathrm{~d}, J=8.4 \mathrm{~Hz}, 1 \mathrm{H}), 7.06(\mathrm{~d}, J=9.2 \mathrm{~Hz}, 1 \mathrm{H}), 7.02(\mathrm{~d}, J=9.2 \mathrm{~Hz}, 2 \mathrm{H})$, $6.58(\mathrm{~s}, 1 \mathrm{H}), 6.38(\mathrm{~s}, 2 \mathrm{H}), 6.01(\mathrm{~s}, 2 \mathrm{H}), 5.32(\mathrm{~s}, 2 \mathrm{H}), 4.63(\mathrm{~d}, J=7.2 \mathrm{~Hz}, 1 \mathrm{H}), 4.14$ (dd, $J_{1}=16.0 \mathrm{~Hz}, J_{2}=12.0$ $\mathrm{Hz}, 3 \mathrm{H}), 3.65(\mathrm{~s}, 6 \mathrm{H}), 3.51-3.36(\mathrm{~m}, 4 \mathrm{H}), 3.18\left(\mathrm{dd}, J_{1}=12.0 \mathrm{~Hz}, J_{2}=4.0 \mathrm{~Hz}, 1 \mathrm{H}\right), 2.63-2.51(\mathrm{~m}, 5 \mathrm{H}), 2.37(\mathrm{~s}$, $3 \mathrm{H}) ;{ }^{13} \mathrm{C}$ NMR (400 MHz, DMSO- $d_{6}$, TMS, ppm) $\delta: 176.26,171.0,158.7,153.86,153.6,147.3,140.4,139.7$, 138.5, 135.1, 132.8, 131.9, 129.7, 129.4, 126.5, 125.6, 115.7, 112.6, 110.5, 110.0, 108.1, 101.7, 70.4, 69.2, $65.3,56.8,52.0,50.5,45.7,43.7,40.5,19.3 ; \mathrm{MS}(\mathrm{ESI}): 783.2536$ for $[\mathrm{M}+\mathrm{H}]^{]}$(calculated 783.7597 for $\mathrm{C}_{40} \mathrm{H}_{38} \mathrm{~N}_{4} \mathrm{O}_{13}$ ).

Data for Compound 2-(4-methyl-2-nitrophenoxy)acetic acid-4ß-N-(4-Nitrophenyl piperazinyl)-4'-0demethyl-4-deoxypodophyllotoxin (2b). ${ }^{1} \mathrm{H}$ NMR (400 MHz, DMSO- $d_{6}$, TMS, ppm): $\delta: 8.07$ (d, J=9.2Hz, 2H),7.72 (s, 1H),7.51 (d, J=8.4 Hz, 1H), $7.42(\mathrm{~s}, 1 \mathrm{H}), 7.20$ (d, J=8.4 Hz, 1H), 7.04 (d, J=9.2 Hz, 2H), 6.57 (s, $1 \mathrm{H}), 6.38(\mathrm{~s}, 2 \mathrm{H}), 6.01(\mathrm{~s}, 2 \mathrm{H}), 5.30(\mathrm{~s}, 2 \mathrm{H}), 4.59(\mathrm{~d}, J=7.2 \mathrm{~Hz}, 1 \mathrm{H}), 4.14\left(\mathrm{dd}, J_{1}=16.0 \mathrm{~Hz}, J_{2}=12.0 \mathrm{~Hz}, 3 \mathrm{H}\right)$, $3.65(\mathrm{~s}, 6 \mathrm{H}), 3.51-3.35(\mathrm{~m}, 4 \mathrm{H}), 3.18\left(\mathrm{dd}, J_{1}=12.0 \mathrm{~Hz}, J_{2}=4.0 \mathrm{~Hz}, 1 \mathrm{H}\right), 2.63-2.50(\mathrm{~m}, 5 \mathrm{H}), 2.31(\mathrm{~s}, 3 \mathrm{H}) ;{ }^{13} \mathrm{C}$ NMR (400 MHz, DMSO-d ${ }_{6}$ TMS, ppm): $\delta 176.26,171.0,158.7,153.86,153.6,147.3,140.4,139.7,138.5$, $135.1,132.8,131.9,129.7,129.4,126.5,125.6,115.7,112.6,110.5,110.0,108.1,101.7,70.4,69.2,65.3$, $56.8,52.0,50.5,45.7,43.7,40.5,19.3 ; \mathrm{MS}(\mathrm{ESI}): 783.2562 \mathrm{for}[\mathrm{M}+\mathrm{H}]^{+}$(calculated 783.7597 for $\mathrm{C}_{40} \mathrm{H}_{38} \mathrm{~N}_{4} \mathrm{O}_{13}$ ).

Data for Compound 2-(5-methyl-2-nitrophenoxy)acetic acid-4ß-N-(4-Nitrophenyl piperazinyl)-4'-0demethyl-4-deoxypodophyllotoxin (2c). ${ }^{1} \mathrm{H}$ NMR (400 MHz, DMSO- $\left.d_{6}, \mathrm{TMS}, \mathrm{ppm}\right): \delta: 8.06(\mathrm{~d}, J=9.2 \mathrm{~Hz}$, 2H),7.82 (d, J=8.4 Hz, 1H),7.42 (s, 1H), $7.12(\mathrm{~s}, 1 \mathrm{H}), 7.04(\mathrm{~d}, J=9.2 \mathrm{~Hz}, 2 \mathrm{H}), 6.99$ (d, J=8.0 Hz, 1H), 6.57 (s, $1 \mathrm{H}), 6.39(\mathrm{~s}, 2 \mathrm{H}), 6.01(\mathrm{~s}, 2 \mathrm{H}), 5.33(\mathrm{~s}, 2 \mathrm{H}), 4.59(\mathrm{~d}, J=7.2 \mathrm{~Hz}, 1 \mathrm{H}), 4.14\left(\mathrm{dd}, J_{1}=16.0 \mathrm{~Hz}, J_{2}=12.0 \mathrm{~Hz}, 3 \mathrm{H}\right)$, $3.66(\mathrm{~s}, 6 \mathrm{H}), 3.51-3.34(\mathrm{~m}, 4 \mathrm{H}), 3.18\left(\mathrm{dd}, J_{1}=12.0 \mathrm{~Hz}, J_{2}=4.0 \mathrm{~Hz}, 1 \mathrm{H}\right), 2.62-2.50(\mathrm{~m}, 5 \mathrm{H}), 2.35(\mathrm{~s}, 3 \mathrm{H}) ;{ }^{13} \mathrm{C}$ NMR (400 MHz, DMSO- $d_{6}$, TMS, ppm): $\delta 176.26,171.0,158.7,153.86,153.6,147.3,140.4,139.7,138.5$, $135.1,132.8,131.9,129.7,129.4,126.5,125.6,115.7,112.6,110.5,110.0,108.1,101.7,70.4,69.2,65.3$, $56.8,52.0,50.5,45.7,43.7,40.5,19.3 ; \mathrm{MS}(\mathrm{ESI}): 783.2472$ for $[\mathrm{M}+\mathrm{H}]^{+}$(calculated783.7597 for $\mathrm{C}_{40} \mathrm{H}_{38} \mathrm{~N}_{4} \mathrm{O}_{13}$ ).

Data for Compound 2-(5-methyl-2-nitrophenoxy)acetic acid-4ß-N-(4-Nitrophenyl piperazinyl)-4'-0demethyl-4-deoxypodophyllotoxin (2c). ${ }^{1} \mathrm{H}$ NMR (400 MHz, DMSO- $d_{6}$, TMS, ppm): $\delta: 8.06(\mathrm{~d}, J=9.2 \mathrm{~Hz}$, 2H),7.82 (d, J=8.4 Hz, 1H),7.42 (s, 1H), $7.12(\mathrm{~s}, 1 \mathrm{H}), 7.04$ (d, J=9.2 Hz, 2H), 6.99 (d, J=8.0 Hz, 1H), 6.57 (s, 
1H), 6.39 (s, 2H), $6.01(\mathrm{~s}, 2 \mathrm{H}), 5.33(\mathrm{~s}, 2 \mathrm{H}), 4.59$ (d, J=7.2 Hz, 1H), 4.14 (dd, $J_{7}=16.0 \mathrm{~Hz}, J_{2}=12.0 \mathrm{~Hz}, 3 \mathrm{H}$ ), $3.66(\mathrm{~s}, 6 \mathrm{H}), 3.51-3.34(\mathrm{~m}, 4 \mathrm{H}), 3.18\left(\mathrm{dd}, J_{1}=12.0 \mathrm{~Hz}, J_{2}=4.0 \mathrm{~Hz}, 1 \mathrm{H}\right), 2.62-2.50(\mathrm{~m}, 5 \mathrm{H}), 2.35(\mathrm{~s}, 3 \mathrm{H}) ;{ }^{13} \mathrm{C}$ NMR (400 MHz, DMSO-d ${ }_{6}$ TMS, ppm): $8176.26,171.0,158.7,153.86,153.6,147.3,140.4,139.7,138.5$, $135.1,132.8,131.9,129.7,129.4,126.5,125.6,115.7,112.6,110.5,110.0,108.1,101.7,70.4,69.2,65.3$, $56.8,52.0,50.5,45.7,43.7,40.5,19.3 ; \mathrm{MS}(\mathrm{ESI}): 783.2472$ for $[\mathrm{M}+\mathrm{H}]^{+}$(calculated783.7597 for $\mathrm{C}_{40} \mathrm{H}_{38} \mathrm{~N}_{4} \mathrm{O}_{13}$ ).

Data for Compound 2-(4-methoxy-2-nitrophenoxy)acetic acid-4ß-N-(4-Nitrophenyl piperazinyl)-4'-0demethyl-4-deoxypodophyllotoxin (2d). ${ }^{1} \mathrm{H}$ NMR (400 MHz, DMSO-d 6 , TMS, ppm): $\delta: 8.06$ (d, J=9.2Hz, 2H),7.47 (s, 1H),7.42 (s, 1H), 7.28 (d, J=8.0 Hz, 2H), $7.04(\mathrm{~d}, J=8.0 \mathrm{~Hz}, 2 \mathrm{H}), 6.57(\mathrm{~s}, 1 \mathrm{H}), 6.38(\mathrm{~s}, 2 \mathrm{H}), 6.01$ $(\mathrm{s}, 2 \mathrm{H}), 5.25(\mathrm{~s}, 2 \mathrm{H}), 4.59(\mathrm{~d}, \mathrm{~J}=4.0 \mathrm{~Hz}, 1 \mathrm{H}), 4.14\left(\mathrm{dd}, J_{1}=16.0 \mathrm{~Hz}, J_{2}=12.0 \mathrm{~Hz}, 3 \mathrm{H}\right), 3.79(\mathrm{~s}, 3 \mathrm{H}), 3.64(\mathrm{~s}, 6 \mathrm{H})$, 3.51-3.35 (m, 4H), $3.18\left(\mathrm{dd}, J_{1}=12.0 \mathrm{~Hz}, J_{2}=4.0 \mathrm{~Hz}, 1 \mathrm{H}\right), 2.63-2.51(\mathrm{~m}, 5 \mathrm{H}){ }^{13} \mathrm{C}$ NMR $\left(400 \mathrm{MHz}\right.$, DMSO- $d_{6}$, TMS, ppm): $\delta 176.26,171.0,158.7,153.86,153.6,147.3,140.4,139.7,138.5,135.1,132.8,131.9,129.7$, $129.4,126.5,125.6,115.7,112.6,110.5,110.0,108.1,101.7,70.4,69.2,65.3,56.8,52.0,50.5,45.7,43.7$, 40.5, 19.3; MS(ESI):799.2507 for $[\mathrm{M}+\mathrm{H}]^{+}$(calculated 799.7582 for $\mathrm{C}_{40} \mathrm{H}_{38} \mathrm{~N}_{4} \mathrm{O}_{14}$ ).

Data for Compound 2-(5-methoxy-2-nitrophenoxy)acetic acid-4ß-N-(4-Nitrophenyl piperazinyl)-4'-0demethyl-4-deoxypodophyllotoxin (2e). ${ }^{1} \mathrm{H}$ NMR (400 MHz, DMSO- $d_{6}$, TMS, ppm): $\delta: 8.02$ (d, J=8.0 Hz, $2 \mathrm{H}), 7.94(\mathrm{~d}, J=8.0 \mathrm{~Hz}, 1 \mathrm{H}), 7.38(\mathrm{~s}, 1 \mathrm{H}), 7.00(\mathrm{~d}, J=8.0 \mathrm{~Hz}, 2 \mathrm{H}), 6.73(\mathrm{~d}, J=9.2 \mathrm{~Hz}, 2 \mathrm{H}), 6.53(\mathrm{~s}, 1 \mathrm{H}), 6.35$ (s, 2H), 5.97 (s, 2H), 5.33 (s, 2H), $4.58(\mathrm{~d}, J=4.0 \mathrm{~Hz}, 1 \mathrm{H}), 4.09$ (dd, $\left.J_{1}=8.0 \mathrm{~Hz}, J_{2}=4.0 \mathrm{~Hz}, 3 \mathrm{H}\right), 3.85(\mathrm{~s}, 3 \mathrm{H}), 3.60$ $(\mathrm{s}, 6 \mathrm{H}), 3.47-3.31(\mathrm{~m}, 4 \mathrm{H}), 3.14\left(\mathrm{dd}, J_{1}=12.0 \mathrm{~Hz}, J_{2}=4.0 \mathrm{~Hz}, 1 \mathrm{H}\right), 2.61-2.46(\mathrm{~m}, 5 \mathrm{H}) ;{ }^{13} \mathrm{C} \mathrm{NMR}(400 \mathrm{MHz}$, DMSO- $d_{6}$, TMS, ppm): $\delta 176.26,171.0,158.7,153.86,153.6,147.3,140.4,139.7,138.5,135.1,132.8$, 131.9, 129.7, 129.4, 126.5, 125.6, 115.7, 112.6, 110.5, 110.0, 108.1, 101.7, 70.4, 69.2, 65.3, 56.8, 52.0, 50.5, 45.7, 43.7, 40.5, 19.3; MS(ESI):799.2469 for $[\mathrm{M}+\mathrm{H}]^{+}$(calculated 799.7582 for $\mathrm{C}_{40} \mathrm{H}_{38} \mathrm{~N}_{4} \mathrm{O}_{14}$ ).

Data for Compound 2-(3-fluoro-2-nitrophenoxy)acetic acid-4ß-N-(4-Nitrophenyl piperazinyl)-4'-0-demethyl4-deoxypodophyllotoxin (2f). ${ }^{1} \mathrm{H}$ NMR (400 MHz, DMSO-d ${ }_{6}, \mathrm{TMS}, \mathrm{ppm}$ ): $\delta: 8.04$ (d, J=9.2Hz, 2H),7.89(dd, $\left.J_{7}=8.0 \mathrm{~Hz}, J_{2}=4.0 \mathrm{~Hz}, 1 \mathrm{H}\right), 7.66-7.62(\mathrm{~m}, 1 \mathrm{H}), 7.41(\mathrm{~s}, 1 \mathrm{H}), 7.36\left(\mathrm{dd}, J_{1}=12.0 \mathrm{~Hz}, J_{2}=4.0 \mathrm{~Hz}, 1 \mathrm{H}\right), 7.02(\mathrm{~d}$, $J=9.2 \mathrm{~Hz}, 2 \mathrm{H}), 6.55(\mathrm{~s}, 1 \mathrm{H}), 6.37(\mathrm{~s}, 2 \mathrm{H}), 5.99(\mathrm{~s}, 2 \mathrm{H}), 5.32(\mathrm{~s}, 2 \mathrm{H}), 4.57(\mathrm{~d}, J=4.4 \mathrm{~Hz}, 1 \mathrm{H}), 4.12\left(\mathrm{dd}, J_{7}=16.0\right.$ $\left.\mathrm{Hz}, J_{2}=8.0 \mathrm{~Hz}, 3 \mathrm{H}\right), 3.63(\mathrm{~s}, 6 \mathrm{H}), 3.49-3.35(\mathrm{~m}, 4 \mathrm{H}), 3.16\left(\mathrm{dd}, J_{1}=12.0 \mathrm{~Hz}, J_{2}=4.0 \mathrm{~Hz}, 1 \mathrm{H}\right), 2.62-2.49(\mathrm{~m}, 5 \mathrm{H})$; ${ }^{13} \mathrm{C}$ NMR $\left(400 \mathrm{MHz}\right.$, DMSO- $d_{6}$, TMS, ppm): $\delta 176.26,171.0,158.7,153.86,153.6,147.3,140.4,139.7$, $138.5,135.1,132.8,131.9,129.7,129.4,126.5,125.6,115.7,112.6,110.5,110.0,108.1,101.7,70.4,69.2$, $65.3,56.8,52.0,50.5,45.7,43.7,40.5,19.3 ; \mathrm{MS}(\mathrm{ESI}): 787.2260$ for $[\mathrm{M}+\mathrm{H}]^{+}$(calculated 787.7220 for $\left.\mathrm{C}_{39} \mathrm{H}_{35} \mathrm{FN}_{4} \mathrm{O}_{13}\right)$.

Data for Compound 2-(4-fluoro-2-nitrophenoxy)acetic acid-4ß-N-(4-Nitrophenyl piperazinyl)-4'-0-demethyl4-deoxypodophyllotoxin (2g). ${ }^{1} \mathrm{H}$ NMR (400 MHz, DMSO- $d_{6}$, TMS, ppm): $\delta: 8.05$ (d, J=8.0 Hz, 2H), 7.68 (dd, $\left.J_{1}=16.0 \mathrm{~Hz}, J_{2}=8.0 \mathrm{~Hz}, 1 \mathrm{H}\right), 7.41(\mathrm{~s}, 1 \mathrm{H}), 7.19\left(\mathrm{dd}, J_{1}=24.0 \mathrm{~Hz}, J_{2}=12.0 \mathrm{~Hz}, 2 \mathrm{H}\right), 7.02(\mathrm{~d}, J=9.2 \mathrm{~Hz}, 2 \mathrm{H}), 6.56$ 
(s, 1H), 6.37 (s, 2H), $5.99(\mathrm{~s}, 2 \mathrm{H}), 5.38(\mathrm{~s}, 2 \mathrm{H}), 4.57(\mathrm{~d}, \mathrm{~J}=4.4 \mathrm{~Hz}, 1 \mathrm{H}), 4.12\left(\mathrm{dd}, J_{1}=16.0 \mathrm{~Hz}, J_{2}=8.0 \mathrm{~Hz}, 3 \mathrm{H}\right)$, $3.64(\mathrm{~s}, 6 \mathrm{H}), 3.62-3.45(\mathrm{~m}, 4 \mathrm{H}), 3.16\left(\mathrm{dd}, J_{1}=12.0 \mathrm{~Hz}, J_{2}=4.0 \mathrm{~Hz}, 1 \mathrm{H}\right), 2.62-2.49(\mathrm{~m}, 5 \mathrm{H}) ;{ }^{13} \mathrm{C}$ NMR $(400$ MHz, DMSO- $d_{6}$, TMS, ppm): $\delta 176.26,171.0,158.7,153.86,153.6,147.3,140.4,139.7,138.5,135.1,132.8$, $131.9,129.7,129.4,126.5,125.6,115.7,112.6,110.5,110.0,108.1,101.7,70.4,69.2,65.3,56.8,52.0,50.5$, 45.7, 43.7, 40.5, 19.3; MS(ESI):787.2280 for $[\mathrm{M}+\mathrm{H}]^{+}$(calculated 787.7220 for $\mathrm{C}_{39} \mathrm{H}_{35} \mathrm{FN}_{4} \mathrm{O}_{13}$ ).

Data for Compound 2-(5-fluoro-2-nitrophenoxy)acetic acid-4ß-N-(4-Nitrophenyl piperazinyl)-4'-0-demethyl4-deoxypodophyllotoxin (2h). ${ }^{1} \mathrm{H}$ NMR (400 MHz, DMSO-d ${ }_{6}$, TMS, ppm): $\delta: 8.02$ (d, J=8.0 Hz, 2H),7.76 (dd, $\left.J_{7}=16.0 \mathrm{~Hz}, J_{2}=8.0 \mathrm{~Hz}, 1 \mathrm{H}\right), 7.39(\mathrm{~s}, 1 \mathrm{H}), 7.19\left(\mathrm{dd}, J_{7}=24.0 \mathrm{~Hz}, J_{2}=12.0 \mathrm{~Hz}, 2 \mathrm{H}\right), 7.02(\mathrm{~d}, J=9.2 \mathrm{~Hz}, 2 \mathrm{H}), 6.53$ (s, 1H), $6.35(\mathrm{~s}, 2 \mathrm{H}), 5.97(\mathrm{~s}, 2 \mathrm{H}), 5.39(\mathrm{~s}, 2 \mathrm{H}), 4.58(\mathrm{~d}, J=4.4 \mathrm{~Hz}, 1 \mathrm{H}), 4.12\left(\mathrm{dd}, J_{1}=16.0 \mathrm{~Hz}, J_{2}=8.0 \mathrm{~Hz}, 3 \mathrm{H}\right)$, $3.61(\mathrm{~s}, 6 \mathrm{H}), 3.48-3.29(\mathrm{~m}, 4 \mathrm{H}), 3.16\left(\mathrm{dd}, J_{1}=12.0 \mathrm{~Hz}, J_{2}=4.0 \mathrm{~Hz}, 1 \mathrm{H}\right), 2.62-2.49(\mathrm{~m}, 5 \mathrm{H}) ;{ }^{13} \mathrm{C}$ NMR $(400$ MHz, DMSO- $d_{6}$, TMS, ppm): $\delta 176.26,171.0,158.7,153.86,153.6,147.3,140.4,139.7,138.5,135.1,132.8$, $131.9,129.7,129.4,126.5,125.6,115.7,112.6,110.5,110.0,108.1,101.7,70.4,69.2,65.3,56.8,52.0,50.5$, 45.7, 43.7, 40.5, 19.3; MS(ESI):787.2286 for $[\mathrm{M}+\mathrm{H}]^{+}$(calculated 787.7220 for $\mathrm{C}_{39} \mathrm{H}_{35} \mathrm{FN}_{4} \mathrm{O}_{13}$ ).

Data for Compound 2-(4-bromo-2-nitrophenoxy)acetic acid-4ß-N-(4-Nitrophenyl piperazinyl)-4'-0-demethyl4-deoxypodophyllotoxin (2i). ${ }^{1} \mathrm{H}$ NMR (400 MHz, DMSO-d ${ }_{6}$, TMS, ppm): $\delta: 8.14$ (s, 1H), 8.05 (d, J=8.0Hz, 2H),7.91 (d, J=8.0Hz, 1H), 7.41(s, 1H), $7.28(\mathrm{~d}, J=12.0 \mathrm{~Hz}, 1 \mathrm{H}), 7.03(\mathrm{~d}, J=12.0 \mathrm{~Hz}, 2 \mathrm{H}), 6.55(\mathrm{~s}, 1 \mathrm{H}), 6.37$ $(\mathrm{s}, 2 \mathrm{H}), 6.00(\mathrm{~s}, 2 \mathrm{H}), 5.36(\mathrm{~s}, 2 \mathrm{H}), 4.57(\mathrm{~d}, J=4.0 \mathrm{~Hz}, 1 \mathrm{H}), 4.12$ (dd, $\left.J_{1}=16.0 \mathrm{~Hz}, J_{2}=8.0 \mathrm{~Hz}, 3 \mathrm{H}\right), 3.64(\mathrm{~s}, 6 \mathrm{H})$, 3.50-3.33 (m, 4H), $3.17\left(\mathrm{dd}, J_{1}=16.0 \mathrm{~Hz}, J_{2}=4.0 \mathrm{~Hz}, 1 \mathrm{H}\right), 2.62-2.49(\mathrm{~m}, 5 \mathrm{H}) ;{ }^{13} \mathrm{C}$ NMR $\left(400 \mathrm{MHz}, \mathrm{DMSO}-d_{6}\right.$, TMS, ppm): $\delta 176.26,171.0,158.7,153.86,153.6,147.3,140.4,139.7,138.5,135.1,132.8,131.9,129.7$, 129.4, 126.5, 125.6, 115.7, 112.6, 110.5, 110.0, 108.1, 101.7, 70.4, 69.2, 65.3, 56.8, 52.0, 50.5, 45.7, 43.7, 40.5, 19.3; $\mathrm{MS}(\mathrm{ESI}): 847.1464$ for $[\mathrm{M}+\mathrm{H}]^{+}$(calculated847.1383 for $\mathrm{C}_{39} \mathrm{H}_{35} \mathrm{BrN}_{4} \mathrm{O}_{13}$ ).

Data for Compound 2-(5-bromo-2-nitrophenoxy)acetic acid-4ß-N-(4-Nitrophenyl piperazinyl)-4'-0-demethyl4-deoxypodophyllotoxin (2j). ${ }^{1} \mathrm{H}$ NMR (400 MHz, DMSO-d ${ }_{6}$ TMS, ppm): $\delta: 8.05$ (d, J=8.0 Hz, 2H),7.87 (d, $J=8.4 \mathrm{~Hz}, 1 \mathrm{H}), 7.54(\mathrm{~s}, 1 \mathrm{H}), 7.40(\mathrm{~d}, J=8.0 \mathrm{~Hz}, 2 \mathrm{H}), 7.02(\mathrm{~d}, J=8.0 \mathrm{~Hz}, 2 \mathrm{H}), 6.55(\mathrm{~s}, 1 \mathrm{H}), 6.38(\mathrm{~s}, 2 \mathrm{H}), 5.99$ (s, $2 \mathrm{H}), 5.45(\mathrm{~s}, 2 \mathrm{H}), 4.57(\mathrm{~d}, J=4.0 \mathrm{~Hz}, 1 \mathrm{H}), 4.12\left(\mathrm{dd}, J_{7}=16.0 \mathrm{~Hz}, J_{2}=8.0 \mathrm{~Hz}, 3 \mathrm{H}\right), 3.66(\mathrm{~s}, 6 \mathrm{H}), 3.49-3.37(\mathrm{~m}$, $4 \mathrm{H}), 3.17\left(\mathrm{dd}, J_{1}=16.0 \mathrm{~Hz}, J_{2}=4.0 \mathrm{~Hz}, 1 \mathrm{H}\right), 2.62-2.49(\mathrm{~m}, 5 \mathrm{H}) ;{ }^{13} \mathrm{C}$ NMR $\left(400 \mathrm{MHz}\right.$, DMSO- $\left.d_{6}, \mathrm{TMS}, \mathrm{ppm}\right)$ : 8176.26, 171.0, 158.7, 153.86, 153.6, 147.3, 140.4, 139.7, 138.5, 135.1, 132.8, 131.9, 129.7, 129.4, 126.5, 125.6, 115.7, 112.6, 110.5, 110.0, 108.1, 101.7, 70.4, 69.2, 65.3, 56.8, 52.0, 50.5, 45.7, 43.7, 40.5, 19.3; MS(ESI):847.1489 for $[\mathrm{M}+\mathrm{H}]^{+}$(calculated 847.1383 for $\mathrm{C}_{39} \mathrm{H}_{35} \mathrm{BrN}_{4} \mathrm{O}_{13}$ ).

Data for Compound 2-(5-chloro-2-nitrophenoxy) acetic acid-4ß-N-(4-Nitrophenyl piperazinyl)-4'-0demethyl-4-deoxypodophyllotoxin (2k). ${ }^{1} \mathrm{H}$ NMR (400 MHz, DMSO- $\left.d_{6}, \mathrm{TMS}, \mathrm{ppm}\right): \delta: 8.07$ (d, J=9.2Hz, 2H),7.97 (d, J=8.8 Hz, 1H),7.43 (d, J=3.2 Hz, 2H), 7.38 (d, J=8.8 Hz, 1H), $7.04(\mathrm{~d}, J=9.2 \mathrm{~Hz}, 2 \mathrm{H}), 6.57$ (s, $1 \mathrm{H}), 6.39(\mathrm{~s}, 2 \mathrm{H}), 6.01(\mathrm{~s}, 2 \mathrm{H}), 5.46(\mathrm{~s}, 2 \mathrm{H}), 4.59(\mathrm{~d}, J=4.4 \mathrm{~Hz}, 1 \mathrm{H}), 4.14\left(\mathrm{dd}, J_{1}=16.0 \mathrm{~Hz}, J_{2}=12.0 \mathrm{~Hz}, 3 \mathrm{H}\right)$, $3.66(\mathrm{~s}, 6 \mathrm{H}), 3.52-3.36(\mathrm{~m}, 4 \mathrm{H}), 3.18\left(\mathrm{dd}, J_{1}=12.0 \mathrm{~Hz}, J_{2}=4.0 \mathrm{~Hz}, 1 \mathrm{H}\right), 2.63-2.50(\mathrm{~m}, 5 \mathrm{H}) ;{ }^{13} \mathrm{C} \mathrm{NMR}(400$ 
MHz, DMSO-d $d_{6}$ TMS, ppm): $\delta 176.26,171.0,158.7,153.86,153.6,147.3,140.4,139.7,138.5,135.1,132.8$, $131.9,129.7,129.4,126.5,125.6,115.7,112.6,110.5,110.0,108.1,101.7,70.4,69.2,65.3,56.8,52.0,50.5$, 45.7, 43.7, 40.5, 19.3; MS(ESI):803.1993 for $[\mathrm{M}+\mathrm{H}]^{+}$(calculated 803.1897 for $\left.\mathrm{C}_{39} \mathrm{H}_{35} \mathrm{CIN}_{4} \mathrm{O}_{13}\right)$.

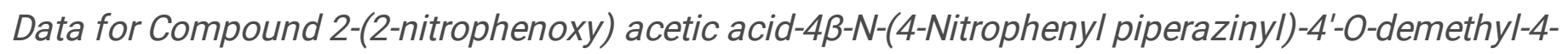
deoxypodophyllotoxin (2I). ${ }^{1} \mathrm{H}$ NMR (400 MHz, DMSO- $\left.d_{6}, \mathrm{TMS}, \mathrm{ppm}\right): \delta$ : 8.06(d, J=8.0 Hz, 1H),7.49(d, $J=8.0 \mathrm{~Hz}, 2 \mathrm{H}), 7.70(\mathrm{t}, J=8.0 \mathrm{~Hz}, 1 \mathrm{H}), 7.42(\mathrm{~s}, 1 \mathrm{H}), 7.31(\mathrm{~d}, J=8.0 \mathrm{~Hz}, 1 \mathrm{H}), 7.18$ (t, J=8.0 Hz, $1 \mathrm{H}), 7.04(\mathrm{~d}$, $J=8.0 \mathrm{~Hz}, 2 \mathrm{H}), 6.57(\mathrm{~s}, 1 \mathrm{H}), 6.38(\mathrm{~s}, 2 \mathrm{H}), 6.01(\mathrm{~s}, 2 \mathrm{H}), 5.34(\mathrm{~s}, 2 \mathrm{H}), 4.59(\mathrm{~d}, \mathrm{~J}=4.0 \mathrm{~Hz}, 1 \mathrm{H}), 4.13\left(\mathrm{dd}, J_{1}=12.0\right.$ $\left.\mathrm{Hz}, J_{2}=8.0 \mathrm{~Hz}, 3 \mathrm{H}\right), 3.65(\mathrm{~s}, 6 \mathrm{H}), 3.51-3.35(\mathrm{~m}, 4 \mathrm{H}), 3.18\left(\mathrm{dd}, J_{1}=12.0 \mathrm{~Hz}, J_{2}=4.0 \mathrm{~Hz}, 1 \mathrm{H}\right), 2.63-2.50(\mathrm{~m}, 5 \mathrm{H})$; ${ }^{13} \mathrm{C}$ NMR (400 MHz, DMSO- $d_{6}$, TMS, ppm): $\delta 176.26,171.0,158.7,153.86,153.6,147.3,140.4,139.7$, 138.5, 135.1, 132.8, 131.9, 129.7, 129.4, 126.5, 125.6, 115.7, 112.6, 110.5, 110.0, 108.1, 101.7, 70.4, 69.2, $65.3,56.8,52.0,50.5,45.7,43.7,40.5,19.3$; MS(ESI):769.2347 for $[\mathrm{M}+\mathrm{H}]^{+}$(calculated 769.2287 for $\left.\mathrm{C}_{39} \mathrm{H}_{36} \mathrm{~N}_{4} \mathrm{O}_{13}\right)$.

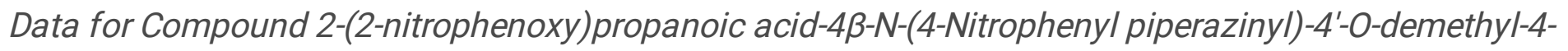
deoxypodophyllotoxin (2m). ${ }^{1} \mathrm{H}$ NMR (400 MHz, DMSO- $\left.d_{6}, \mathrm{TMS}, \mathrm{ppm}\right): \delta$ : $8.04(\mathrm{~d}, \mathrm{~J}=4.0 \mathrm{~Hz}, 2 \mathrm{H}), 7.85$ (d, $J=8.0 \mathrm{~Hz}, 1 \mathrm{H}), 7.66(\mathrm{t}, J=4.0 \mathrm{~Hz}, 1 \mathrm{H}), 7.38(\mathrm{~s}, 1 \mathrm{H}), 7.24(\mathrm{~d}, J=8.0 \mathrm{~Hz}, 1 \mathrm{H}), 7.14(\mathrm{t}, J=8.0 \mathrm{~Hz}, 1 \mathrm{H}), 7.01(\mathrm{~d}$, $J=4.0 \mathrm{~Hz}, 2 \mathrm{H}), 6.53(\mathrm{~s}, 1 \mathrm{H}), 6.33(\mathrm{~s}, 2 \mathrm{H}), 5.96(\mathrm{~s}, 2 \mathrm{H}), 5.46\left(\mathrm{dd}, J_{1}=12.0 \mathrm{~Hz}, J_{2}=4.0 \mathrm{~Hz}, 1 \mathrm{H}\right), 4.54(\mathrm{~d}, J=4.0$ $\mathrm{Hz}, 1 \mathrm{H}), 4.09$ (dd, $\left.J_{1}=16.0 \mathrm{~Hz}, J_{2}=8.0 \mathrm{~Hz}, 3 \mathrm{H}\right), 3.58(\mathrm{~s}, 6 \mathrm{H}), 3.47-3.31(\mathrm{~m}, 4 \mathrm{H}), 3.13\left(\mathrm{dd}, J_{1}=12.0 \mathrm{~Hz}, J_{2}=4.0\right.$ $\mathrm{Hz}, 1 \mathrm{H}), 2.58-2.46(\mathrm{~m}, 5 \mathrm{H}), 1.63(\mathrm{~d}, \mathrm{~J}=8.0 \mathrm{~Hz}, 3 \mathrm{H}) ;{ }^{13} \mathrm{C}$ NMR (400 MHz, DMSO- $\left.d_{6}, \mathrm{TMS}, \mathrm{ppm}\right): \delta 176.26$, 171.0, 158.7, 153.86, 153.6, 147.3, 140.4, 139.7, 138.5, 135.1, 132.8, 131.9, 129.7, 129.4, 126.5, 125.6, 115.7, 112.6, 110.5, 110.0, 108.1, 101.7, 70.4, 69.2, 65.3, 56.8, 52.0, 50.5, 45.7, 43.7, 40.5, 19.3;

$\mathrm{MS}(\mathrm{ESI}): 783.2518$ for $[\mathrm{M}+\mathrm{H}]^{+}$(calculated 783.7594 for $\mathrm{C}_{40} \mathrm{H}_{38} \mathrm{~N}_{4} \mathrm{O}_{13}$ ).

Data for Compound 2-methyl-2-(2-nitrophenoxy)propanoic acid-4 $\beta$-N-(4-Nitrophenyl piperazinyl)-4'-Odemethyl-4-deoxypodophyllotoxin (2n). ${ }^{1} \mathrm{H}$ NMR (400 MHz, DMSO-d 6 , TMS, ppm): $\delta: 8.06(\mathrm{~d}, \mathrm{~J}=8.0 \mathrm{~Hz}$, $2 \mathrm{H}), 7.98(\mathrm{~d}, \mathrm{~J}=8.0 \mathrm{~Hz}, 1 \mathrm{H}), 7.66(\mathrm{t}, \mathrm{J}=4.0 \mathrm{~Hz}, 1 \mathrm{H}), 7.42(\mathrm{~s}, 1 \mathrm{H}), 7.24(\mathrm{~d}, J=8.0 \mathrm{~Hz}, 1 \mathrm{H}), 7.18(\mathrm{t}, J=4.0 \mathrm{~Hz}, 1 \mathrm{H})$, 7.01 (d, J=4.0 Hz, 2H), 6.57 (s, 1H), 6.39 (s, 2H), 6.01 (s, 2H), 4.58 (d, J=4.0 Hz, 1H), 4.12 (dd, J =8.0 Hz, $\left.J_{2}=4.0 \mathrm{~Hz}, 3 \mathrm{H}\right), 3.64(\mathrm{~s}, 6 \mathrm{H}), 3.51-3.34(\mathrm{~m}, 4 \mathrm{H}), 3.18\left(\mathrm{dd}, J_{1}=12.0 \mathrm{~Hz}, J_{2}=4.0 \mathrm{~Hz}, 1 \mathrm{H}\right), 2.62-2.49(\mathrm{~m}, 5 \mathrm{H}), 1.98$ $(\mathrm{s}, 6 \mathrm{H}) ;{ }^{13} \mathrm{C}$ NMR $\left(400 \mathrm{MHz}\right.$, DMSO- $\left.d_{6}, \mathrm{TMS}, \mathrm{ppm}\right): \delta 176.26,171.0,158.7,153.86,153.6,147.3,140.4$, 139.7, 138.5, 135.1, 132.8, 131.9, 129.7, 129.4, 126.5, 125.6, 115.7, 112.6, 110.5, 110.0, 108.1, 101.7, 70.4,

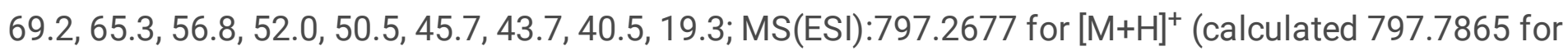
$\left.\mathrm{C}_{41} \mathrm{H}_{40} \mathrm{~N}_{4} \mathrm{O}_{13}\right)$.

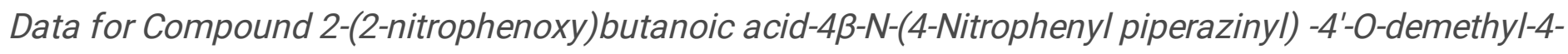
deoxypodophyllotoxin (2o). ${ }^{1} \mathrm{H}$ NMR (400 MHz, DMSO- $\left.d_{6}, \mathrm{TMS}, \mathrm{ppm}\right) \delta: 8.04$ (d, J=4.0 Hz, $\left.2 \mathrm{H}\right), 7.85$ (d, $J=8.0 \mathrm{~Hz}, 1 \mathrm{H}), 7.66(\mathrm{t}, J=4.0 \mathrm{~Hz}, 1 \mathrm{H}), 7.38(\mathrm{~s}, 1 \mathrm{H}), 7.24(\mathrm{~d}, J=8.0 \mathrm{~Hz}, 1 \mathrm{H}), 7.14(\mathrm{t}, J=8.0 \mathrm{~Hz}, 1 \mathrm{H}), 7.01(\mathrm{~d}$, $J=4.0 \mathrm{~Hz}, 2 \mathrm{H}), 6.53(\mathrm{~s}, 1 \mathrm{H}), 6.33(\mathrm{~s}, 2 \mathrm{H}), 5.96(\mathrm{~s}, 2 \mathrm{H}), 5.46(\mathrm{t}, J=4.0 \mathrm{~Hz}, 1 \mathrm{H}), 4.54$ (d, J=4.0 Hz, $1 \mathrm{H}), 4.09$ (dd, $\left.J_{1}=16.0 \mathrm{~Hz}, J_{2}=8.0 \mathrm{~Hz}, 3 \mathrm{H}\right), 3.58(\mathrm{~s}, 6 \mathrm{H}), 3.47-3.31(\mathrm{~m}, 4 \mathrm{H}), 3.13\left(\mathrm{dd}, J_{1}=12.0 \mathrm{~Hz}, J_{2}=4.0 \mathrm{~Hz}, 1 \mathrm{H}\right), 2.58-2.46$ 
$(\mathrm{m}, 5 \mathrm{H}), 1.94-1.80(\mathrm{~m}, 2 \mathrm{H}), 1.47(\mathrm{t}, J=8.0 \mathrm{~Hz}, 3 \mathrm{H}) ;{ }^{13} \mathrm{C}$ NMR (400 MHz, DMSO- $\left.d_{6}, \mathrm{TMS}, \mathrm{ppm}\right): 8176.26$, $171.0,158.7,153.86,153.6,147.3,140.4,139.7,138.5,135.1,132.8,131.9,129.7,129.4,126.5,125.6$, $115.7,112.6,110.5,110.0,108.1,101.7,70.4,69.2,65.3,56.8,52.0,50.5,45.7,43.7,40.5,19.3$; MS(ESI):797.2673 for $[\mathrm{M}+\mathrm{H}]^{+}$(calculated 797.7865 for $\mathrm{C}_{41} \mathrm{H}_{40} \mathrm{~N}_{4} \mathrm{O}_{13}$ ).

Data for Compound 2-methyl-2-(4-methyl-2-nitrophenoxy) prop-anoic acid-4 $\beta$-N-(4-Nitrophenyl piperazinyl)-4'-0-demethyl-4-deoxypodophyllotoxin (2p). ${ }^{1} \mathrm{H}$ NMR (400 MHz, DMSO- $d_{6}$, TMS, ppm) $\delta$ : 8.07(d, J=9.2Hz, 2H),7.72 (s, 1H),7.50 (d, J=8.0 Hz, 1H), 7.43 (s, 1H), 7.20 (d, J=8.0 Hz, 1H), 7.03 (d, J=12.0 $\mathrm{Hz}, 2 \mathrm{H}), 6.57$ (s, 1H), $6.39(\mathrm{~s}, 2 \mathrm{H}), 6.01(\mathrm{~s}, 2 \mathrm{H}), 4.59$ (d, J=4.0 Hz, 1H), 4.14 (dd, $\left.J_{1}=8.0 \mathrm{~Hz}, J_{2}=4.0 \mathrm{~Hz}, 3 \mathrm{H}\right)$, 3.65(s, 6H), 3.51-3.35 (m, 4H), $3.18\left(\mathrm{dd}, J_{1}=12.0 \mathrm{~Hz}, J_{2}=4.0 \mathrm{~Hz}, 1 \mathrm{H}\right), 2.63-2.49(\mathrm{~m}, 5 \mathrm{H}), 2.30(\mathrm{~s}, 3 \mathrm{H}), 1.69(\mathrm{~s}$, $6 \mathrm{H}) ;{ }^{13} \mathrm{C}$ NMR (400 MHz, DMSO- $d_{6}$, TMS, ppm): $\delta 176.26,171.0,158.7,153.86,153.6,147.3,140.4,139.7$, $138.5,135.1,132.8,131.9,129.7,129.4,126.5,125.6,115.7,112.6,110.5,110.0,108.1,101.7,70.4,69.2$, $65.3,56.8,52.0,50.5,45.7,43.7,40.5,19.3 ; \mathrm{MS}(\mathrm{ESI}): 811.2916$ for $[\mathrm{M}+\mathrm{H}]^{+}$(calculated 811.8137 for $\left.\mathrm{C}_{42} \mathrm{H}_{42} \mathrm{~N}_{4} \mathrm{O}_{13}\right)$.

Data for Compound 2-methyl-2-(5-methyl-2-nitrophenoxy) prop-anoic acid-4 $\beta$-N-(4-Nitrophenyl piperazinyl)-4'-O-demethyl-4-deoxypodophyllotoxin (2q). ${ }^{1} \mathrm{H}$ NMR $\left(400 \mathrm{MHz}, \mathrm{DMSO}-d_{6}, \mathrm{TMS}, \mathrm{ppm}\right) \delta$ : 8.06(d, J=8.0 Hz, 2H),7.79 (d, J=8.0Hz, 1H),7.43 (s, 1H), 7.27 (s, 1H), 7.18 (d, J=8.0 Hz, 1H), 7.01 (d, J=12.0 $\mathrm{Hz}, 2 \mathrm{H}), 6.57(\mathrm{~s}, 1 \mathrm{H}), 6.38(\mathrm{~s}, 2 \mathrm{H}), 6.01(\mathrm{~s}, 2 \mathrm{H}), 4.60(\mathrm{~d}, J=4.0 \mathrm{~Hz}, 1 \mathrm{H}), 4.14\left(\mathrm{dd}, J_{1}=8.0 \mathrm{~Hz}, J_{2}=4.0 \mathrm{~Hz}, 3 \mathrm{H}\right)$, 3.67(s, 6H), 3.51-3.35 (m, 4H), $3.18\left(\mathrm{dd}, J_{1}=12.0 \mathrm{~Hz}, J_{2}=4.0 \mathrm{~Hz}, 1 \mathrm{H}\right), 2.62-2.50(\mathrm{~m}, 5 \mathrm{H}), 2.27(\mathrm{~s}, 3 \mathrm{H}), 1.67(\mathrm{~s}$, $6 \mathrm{H}) ;{ }^{13} \mathrm{C}$ NMR (400 MHz, DMSO- $d_{6}$, TMS, ppm): $\delta 176.26,171.0,158.7,153.86,153.6,147.3,140.4,139.7$, 138.5, 135.1, 132.8, 131.9, 129.7, 129.4, 126.5, 125.6, 115.7, 112.6, 110.5, 110.0, 108.1, 101.7, 70.4, 69.2, $65.3,56.8,52.0,50.5,45.7,43.7,40.5,19.3$; MS(ESI):811.4158 for $[\mathrm{M}+\mathrm{H}]^{+}$(calculated 811.8137 for $\left.\mathrm{C}_{42} \mathrm{H}_{42} \mathrm{~N}_{4} \mathrm{O}_{13}\right)$.

Data for Compound 2-(5-bromo-2-nitrophenoxy)-2-methylprop-anoic acid-4 $\beta$ - $N$ - (4-Nitrophenyl piperazinyl) -4'-O-demethyl-4-deoxypodophyllotoxin (2r). ${ }^{1} \mathrm{H}$ NMR (400 MHz, DMSO- $d_{6}$, TMS, ppm) $\delta: 8.07$ (d, J=8.0 Hz, 2H),7.82 (d, J=8.4 Hz, 1H), $7.53(\mathrm{~s}, 1 \mathrm{H}), 7.42(\mathrm{~s}, 1 \mathrm{H}), 7.39(\mathrm{~d}, J=8.0 \mathrm{~Hz}, 1 \mathrm{H}), 7.02(\mathrm{~d}, J=8.0 \mathrm{~Hz}, 2 \mathrm{H}), 6.56(\mathrm{~s}$, $1 \mathrm{H}), 6.38(\mathrm{~s}, 2 \mathrm{H}), 5.99(\mathrm{~s}, 2 \mathrm{H}), 4.59(\mathrm{~d}, J=4.0 \mathrm{~Hz}, 1 \mathrm{H}), 4.11\left(\mathrm{dd}, J_{1}=16.0 \mathrm{~Hz}, J_{2}=8.0 \mathrm{~Hz}, 3 \mathrm{H}\right), 3.66(\mathrm{~s}, 6 \mathrm{H})$, 3.49-3.37 (m, 4H), $3.17\left(\mathrm{dd}, J_{1}=16.0 \mathrm{~Hz}, J_{2}=4.0 \mathrm{~Hz}, 1 \mathrm{H}\right), 2.62-2.49(\mathrm{~m}, 5 \mathrm{H}), 1.66(\mathrm{~s}, 6 \mathrm{H}) ;{ }^{13} \mathrm{C}$ NMR $(400$ MHz, DMSO- $d_{6}$, TMS, ppm): $\delta 176.26,171.0,158.7,153.86,153.6,147.3,140.4,139.7,138.5,135.1,132.8$, $131.9,129.7,129.4,126.5,125.6,115.7,112.6,110.5,110.0,108.1,101.7,70.4,69.2,65.3,56.8,52.0,50.5$, 45.7, 43.7, 40.5, 19.3; MS(ESI):876.2146 for $[\mathrm{M}+\mathrm{H}]^{+}$(calculated 876.2067 for $\mathrm{C}_{41} \mathrm{H}_{39} \mathrm{~B}_{\mathrm{r}} \mathrm{N}_{4} \mathrm{O}_{13}$ ).

Data for Compound 2-(4-methyl-2-nitrop-henoxy) propanoic acid-43-N-(4-Nitrophenyl piperazinyl) -4'-Odemethyl-4-deoxypodophyllotoxin (2s). ${ }^{1} \mathrm{H}$ NMR (400 MHz, DMSO-d $d_{6}$ TMS, ppm) $\delta: 8.07$ (d, J=8.0 Hz, 2H),7.71 (s, 1H),7.53 (d, J=8.0 Hz, 1H), $7.42(\mathrm{~s}, 1 \mathrm{H}), 7.15$ (d, J=8.0 Hz, 1H), $7.06(\mathrm{~d}, J=8.0 \mathrm{~Hz}, 2 \mathrm{H}), 6.58$ (s, 1H), 6.38 (s, 2H), 6.01 (s, 2H), 5.46 (dd, $J_{1}=12.0$ Hz, J2=4.0 Hz, 1H), 4.59 (d, J=4.0 Hz, 1H), 4.14 (dd, $\left.J_{1}=16.0 \mathrm{~Hz}, J_{2}=8.0 \mathrm{~Hz}, 3 \mathrm{H}\right), 3.63(\mathrm{~s}, 6 \mathrm{H}), 3.49-3.35(\mathrm{~m}, 4 \mathrm{H}), 3.15\left(\mathrm{dd}, J_{1}=12.0 \mathrm{~Hz}, J_{2}=4.0 \mathrm{~Hz}, 1 \mathrm{H}\right), 2.61-$ 
2.50(m, 5H), $2.31(\mathrm{~s}, 3 \mathrm{H}), 1.65$ (d, J=8.0 Hz, 3H); ${ }^{13} \mathrm{C}$ NMR (400 MHz, DMSO-d $\left.{ }_{6}, \mathrm{TMS}, \mathrm{ppm}\right):$ 8176.26, 171.0, 158.7, 153.86, 153.6, 147.3, 140.4, 139.7, 138.5, 135.1, 132.8, 131.9, 129.7, 129.4, 126.5, 125.6, $115.7,112.6,110.5,110.0,108.1,101.7,70.4,69.2,65.3,56.8,52.0,50.5,45.7,43.7,40.5,19.3$; MS(ESI):797.2598 for $[\mathrm{M}+\mathrm{H}]^{+}$(calculated 797.7868 for $\mathrm{C}_{41} \mathrm{H}_{40} \mathrm{~N}_{4} \mathrm{O}_{13}$ ).

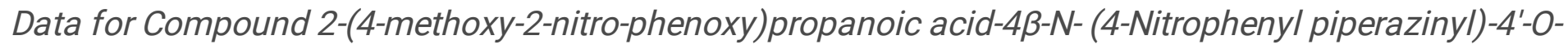
demethyl-4-deoxypodophyllotoxin (2t). ${ }^{1} \mathrm{H}$ NMR (400 MHz, DMSO- $\left.d_{6}, \mathrm{TMS}, \mathrm{ppm}\right) \delta: 8.06(\mathrm{~d}, J=8.0 \mathrm{~Hz}$, 2H),7.49(s, 1H),7.43 (s, 1H), 7.25 (d, J=8.0 Hz, 2H), $7.06(\mathrm{~d}, J=8.0 \mathrm{~Hz}, 2 \mathrm{H}), 6.58(\mathrm{~s}, 1 \mathrm{H}), 6.38(\mathrm{~s}, 2 \mathrm{H}), 6.01$ (s, 2H), $5.42\left(\mathrm{dd}, J_{7}=12.0 \mathrm{~Hz}, J_{2}=4.0 \mathrm{~Hz}, 1 \mathrm{H}\right), 4.61(\mathrm{~d}, J=4.0 \mathrm{~Hz}, 1 \mathrm{H}), 4.14\left(\mathrm{dd}, J_{7}=16.0 \mathrm{~Hz}, J_{2}=8.0 \mathrm{~Hz}, 3 \mathrm{H}\right)$, $3.79(\mathrm{~s}, 3 \mathrm{H}), 3.64(\mathrm{~s}, 6 \mathrm{H}), 3.51-3.39(\mathrm{~m}, 4 \mathrm{H}), 3.18\left(\mathrm{dd}, J_{1}=12.0 \mathrm{~Hz}, J_{2}=4.0 \mathrm{~Hz}, 1 \mathrm{H}\right), 2.63-2.51(\mathrm{~m}, 5 \mathrm{H}), 1.67(\mathrm{~d}$, $J=8.0 \mathrm{~Hz}, 3 \mathrm{H}) ;{ }^{13} \mathrm{C}$ NMR $\left(400 \mathrm{MHz}\right.$, DMSO- $\left.d_{6}, \mathrm{TMS}, \mathrm{ppm}\right): \delta 176.26,171.0,158.7,153.86,153.6,147.3$, $140.4,139.7,138.5,135.1,132.8,131.9,129.7,129.4,126.5,125.6,115.7,112.6,110.5,110.0,108.1$, $101.7,70.4,69.2,65.3,56.8,52.0,50.5,45.7,43.7,40.5,19.3 ; \mathrm{MS}(\mathrm{ESI}): 813.3543$ for $[\mathrm{M}+\mathrm{H}]^{+}$(calculated 813.7857 for $\mathrm{C}_{41} \mathrm{H}_{40} \mathrm{~N}_{4} \mathrm{O}_{14}$ ).

\section{Cytotoxicity assay}

Cells were incubated at $37^{\circ} \mathrm{C}$ in a $5 \% \mathrm{CO}_{2}$ atmosphere. The synthetic compounds $2 \mathrm{a}-2 \mathrm{t}$ and reference compound (Etoposide and Demethylepipodophyllotoxin) were dissolved and the cells were plated in 96well plates determined according to the reported method [16].

\section{Cell cycle and apoptotic assay}

For cell cycle and apoptotic assay were determined according to the reported methods $[25,26]$. Detection of apoptosis using Annexin V-FITC/PI staining, after incubation for $24 \mathrm{~h}$ at $37^{\circ} \mathrm{C}$ in a humidified atmosphere with $5 \% \mathrm{CO}_{2}$, various concentrations of compound $2 \mathrm{~b}$ and $2 \mathrm{~d}$ were added to the cultures, and the plate was incubated for further $72 \mathrm{~h}$. After that, HCT-116 cells were collected, washed, resuspended in $200 \mu \mathrm{L}$ binding buffer of the Annexin V-FITC kit, stained with propidium iodide and incubated for $30 \mathrm{~min}$ at $37^{\circ} \mathrm{C}$ prior to flow cytometric analysis.

\section{Molecular docking model assay}

Based on the redocking process, molecular docking was applied between the chosen two compounds and NTR model. To clarify the binding forms of the chosen compounds, binding affinities were also predicted by using ligand-enzyme molecular docking calculations with different approaches.

\section{Declarations}

Conflict of Interest

\section{Compliance with ethics requirements}


Authors have no financial relationship with the organization that sponsored the research.

CRediT authorship contribution statement:

Zheng-Rong Wu: Software, Data curation, Writing-original draft. Wei Deng: Supervision. Dian He: Funding acquisition, Writing - review. Supervision.

\section{Declaration of Competing Interest}

The authors declare that they have no known competing financial interests or personal relationships that could have appeared to influence the work reported in this paper.

Zheng-Rong Wu

Email: wuzhengrong@lzu.edu.cn

\section{References}

1. Shareef MA, D D, Ramasatyaveni G et al (2015) Eur J Med Chem 89:128

2. Qu Y, Zhang Ch, Ma X, Gao YH et al (2020) Bioorg Med Chem Lett 28(24):115821

3. Thi Q, Le-Nhat-Thuy G, Thi T et al (2021) Bioorg Med Chem Lett 37(4):127841

4. Kamal JR, Tamboli MJ, Ramaiah SF, Adil S (2013) N. C. V. L. P. Bioorg Med Chem 21:6414

5. Yong Y, Shin SY, Lee YH, Lim Y (2009) Bioorg Med Chem Lett 19:4367

6. Chen SW, Gao YY, Zhou NN, Liu J, Huang WT, Hui L, Jin Y, Jin YX (2011) Bioorg Med Chem Lett 21:7355

7. V K, Singh.; R, Roy KH (2014) Eur J Med Chem 74:552

8. Xu H, Lv M, Tian X (2009) Curr Med Chem 16:327

9. Zhao Yu, Ge CWang, Wu ZH, Wang CN, Fang JH, Zhu L (2011) Eur. J. Med. Chem.46,901

10. Wu GR, X B, Yang Y, Q. et al (2018) Eur. J. Med. Chem. 155,183

11. Wang L, Yang FY, Yang XC, Guan XH, Hu CQ, Liu T, He QJ, Yang B, Hu Y (2011) Z Eur J Med Chem 46:285

12. Huang WT, Liu J, Liu JF, Hui L, Ding YL, Chen SW (2012) Eur J Med Chem 49:48

13. Kamal A, Suresh P, Ramaiah MJ et al (2011) Bioorg Med Chem 19:4589

14. Liu JF, Sang CY, Xu XH, Zhang LL et al (2013) Eur J Med Chem 64:621

15. Kamal A, Suresh P, Ramaiah MJ, Mallareddy A et al (2012) Bioorg Med Chem 20:2054

16. Liu JF, Sang CY, Qin WW, Zhao J et al (2013) Bioorg Med Chem 21(22):6948

17. W A, Denny (2002) Curr Pharmaceut Des 8:1349

18. Patterson S, Wyllie (2014) Trends Parasitol 30:289

19. Jiang Q, Zhang. Z, Lu J, Huang Y et al (2013) Bioorgan Med Chem 21:7735 
20. Ao X, Bright. SA, Taylor NC, Org RBP (2017) Biomol. Chem. 15, 6104

21. Zhang X, Zhao. Q, Tang Y (2017) Anal Chem 89:5503

22. Zhao Y, Ge CW, Wu ZH, Wang CN, Fang JH, Zhu L (2011) Eur J Med Chem 46:901

23. Zhou Y, Bobba KN, Lv XW, Yang D et al (2017) Analyst 142:345

24. Liu Q, Zhuo J, Xi H et al (2005) Guangzhou Chem 30(4):6

25. Riccardi C, Nicoletti I (2006) Nat Protoc 1:1458

26. Chen S, Cheng AC, Wang MS, Peng X (2008) g. W J G, 14, 2174

\section{Figures}
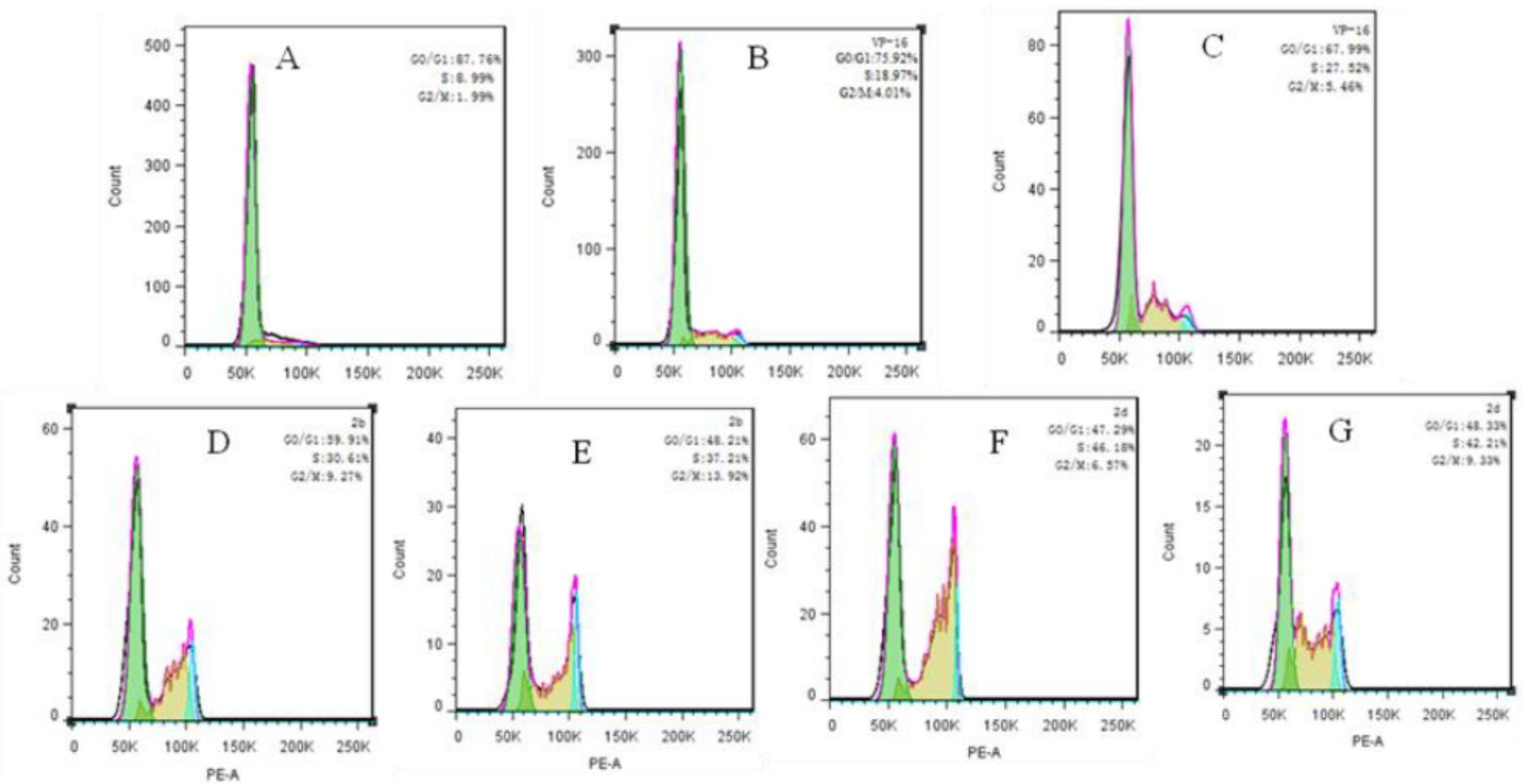

Figure 1

Effects of compound $2 \mathrm{~b}$ and $2 \mathrm{~d}$ on HeLa cells cycle progression (48 h). (A) Control; (B) treated with 2.5 $\mu \mathrm{mol} / \mathrm{L} \mathrm{VP-16;(C)} \mathrm{treated} \mathrm{with} 50 \mu \mathrm{mol} / \mathrm{L}$ VP-16; (D) treated with $2.5 \mu \mathrm{mol} / \mathrm{L} \mathrm{2b;} \mathrm{(E)} \mathrm{treated} \mathrm{with} 50$ $\mu \mathrm{mol} / \mathrm{L} 2 \mathrm{~b} ;(\mathrm{F})$ treated with $50 \mu \mathrm{mol} / \mathrm{L} 2 \mathrm{~d}$; (G)treated with $50 \mu \mathrm{mol} / \mathrm{L} 2 \mathrm{~d}$. 

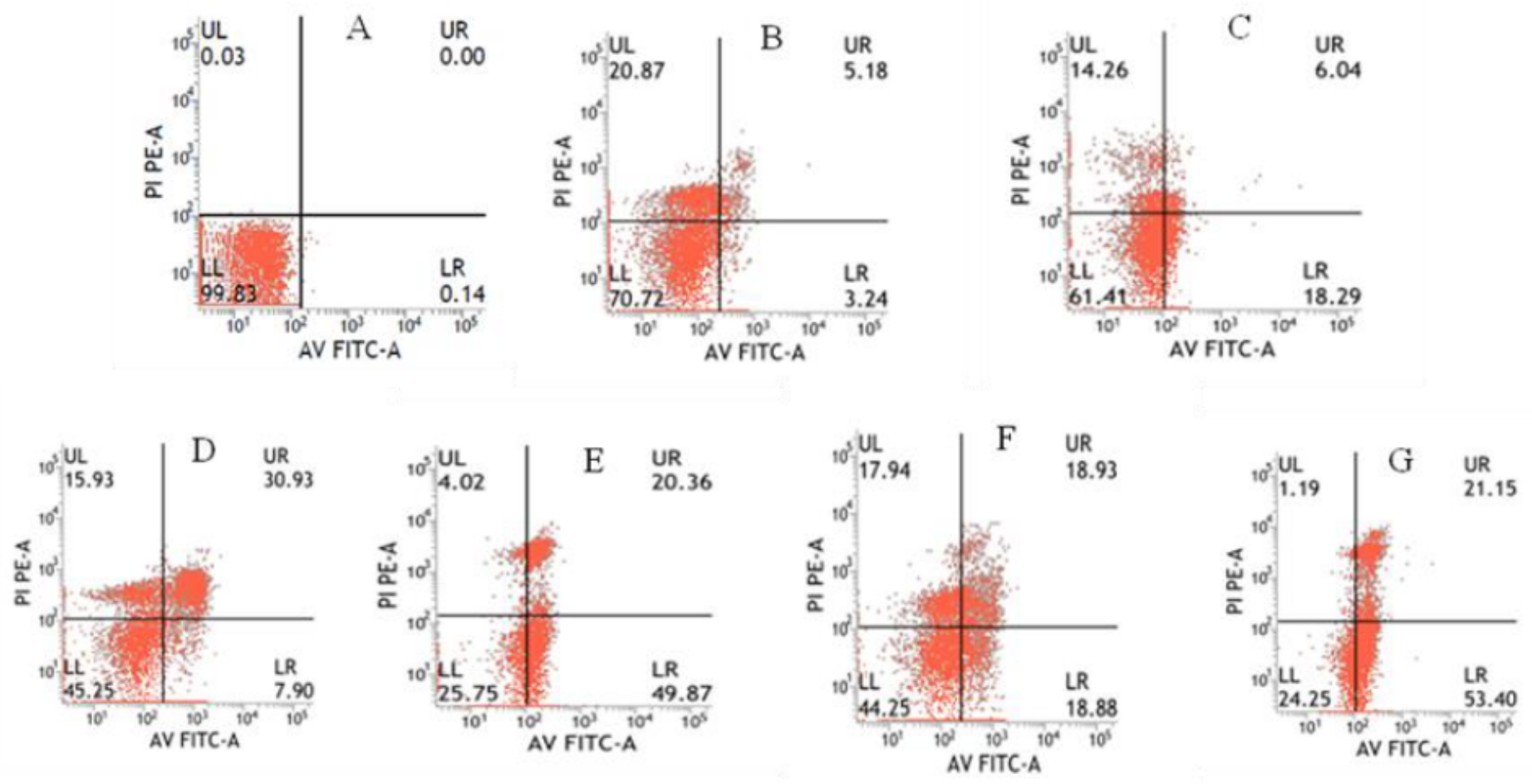

\section{Figure 2}

Apoptosis in HeLa cells were treated with compound $2 \mathrm{~b}$ and $2 \mathrm{~d}$ for $48 \mathrm{~h}$, as detected using flow cytometry with the annexin V/PI apoptosis detection kit. (A) Control; (B) treated with $2.5 \mu \mathrm{mol} / \mathrm{L} \mathrm{VP-16;} \mathrm{(C)} \mathrm{treated}$ with $50 \mu \mathrm{mol} / \mathrm{L}$ VP-16; (D) treated with $2.5 \mu \mathrm{mol} / \mathrm{L} 2 \mathrm{~b}$; (E) treated with $50 \mu \mathrm{mol} / \mathrm{L} 2 \mathrm{~b}$; (F) treated with 50 $\mu \mathrm{mol} / \mathrm{L} 2 \mathrm{~d}$; (G)treated with $50 \mu \mathrm{mol} / \mathrm{L} 2 \mathrm{~d}$. 

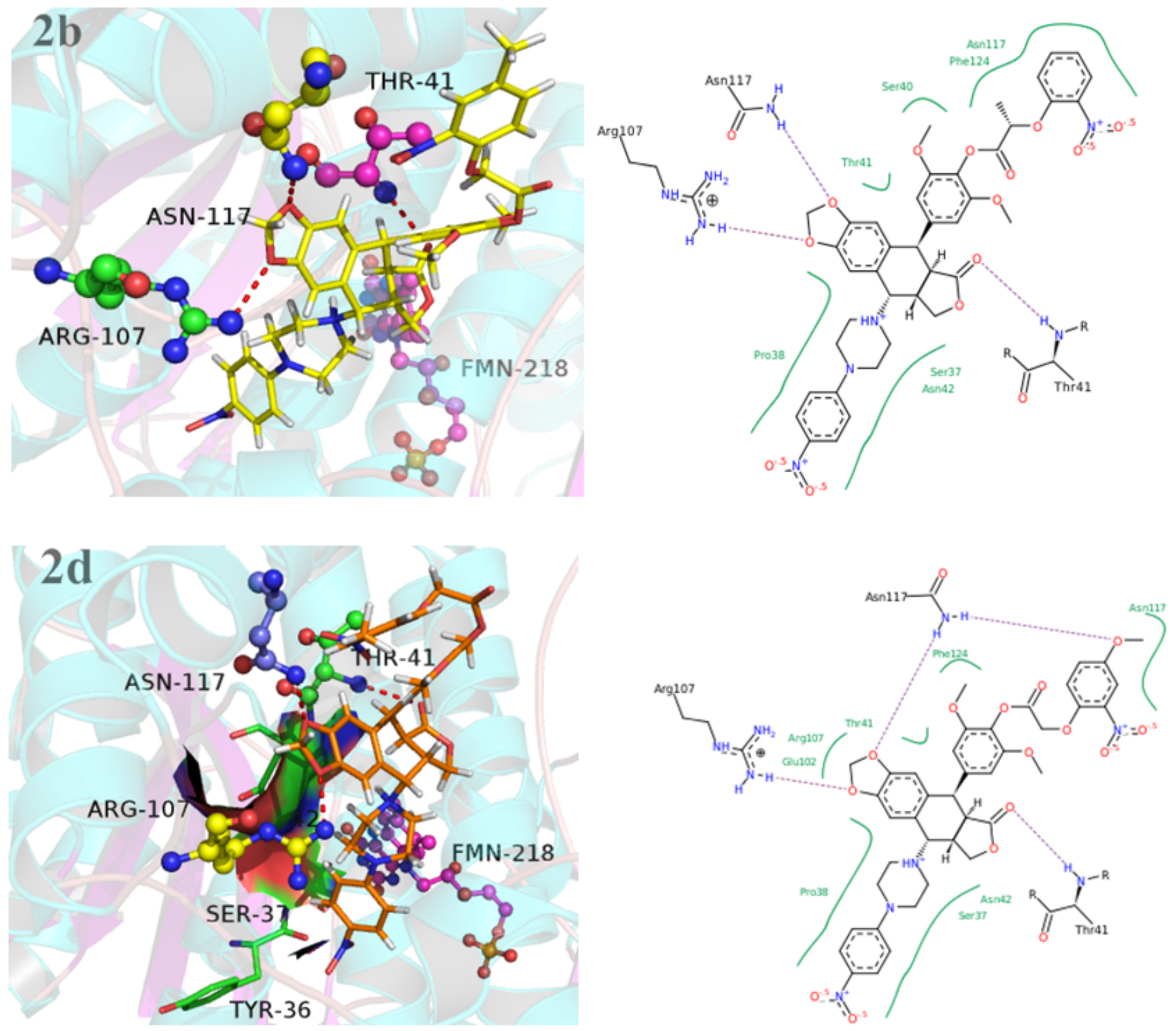

\section{Figure 3}

Molecular binding mode of compound $2 \mathrm{~b}$ and $2 \mathrm{~d}$ to NTR $1 \mathrm{DS} 7$.

\section{Supplementary Files}

This is a list of supplementary files associated with this preprint. Click to download.

- GraphicalAbstract.png

- Scheme1.png

- Supplementarymaterial.docx 